\title{
KOMUNIKASI LINGKUNGAN UNTUK MITIGASI BENCANA ERUPSI GUNUNG SINABUNG
}

\author{
Puji Lestari, Eko Teguh Paripurno, Sari Bahagiarti Kusumayudha, \\ dan Berliyan Ramadhaniyanto \\ Universitas Pembangunan Nasional Veteran Yogyakarta, Jalan Babarsari 2 Yogyakarta, \\ Indonesia, No Telp 08156874669. \\ Email: puji.lestari@upnyk.ac.id
}

\begin{abstract}
This study aims to find a model of environmental communications for disaster mitigation eruption of Mount Sinabung at Karo district of North Sumatra. This research also aims at increasing public awareness and government in improving the effectiveness of disaster communications in Sinabung. Organizational Information Theory is used as concept of his study. The research uses descriptive qualitative method by employing data collection techniques such as Focus Group Discussion (FGD) and interviews on communication training for disaster mitigation at Sinabung. The research located in Karo district of North Sumatra, particularly at Regional Disaster Management Agency (BPBD), Department of Communication and Information Technology, and Kesbanglinmas, Head sub district, Head of village, and volunteers. The result of this research is a model of environmental communications to support early warning system in Sinabung.
\end{abstract}

Keyword: Enviromental Communication, disaster, Sinabung

\begin{abstract}
Abstrak
Penelitian ini bertujuan untuk menemukan model komunikasi lingkungan untuk mitigasi bencana erupsi Gunung Sinabung Kabupaten Karo Sumatera Utara. Manfaat penelitian ini dapat meningkatkan kesadaran masyarakat dan pemerintah dalam meningkatkan efektifitas komunikasi bencana Gunung Sinabung. Teori Informasi Organisasi digunakan sebagai bahan kajian ini. Metode penelitian deskriptif kualitatif dengan teknik pengumpulan data Focus Group Discussion (FGD), wawancara melalui pelatihan komunikasi untuk mitigasi bencana Sinabung. Lokasi penelitian di Kabupaten Karo Sumatera Utara khususnya Badan Pengelolaan Bencana Daerah (BPBD), Dinas Kominfo, dan Kesbanglinmas, Camat, Kepala Desa, dan anggota komunitas peduli bencana. Hasil penelitian berupa model komunikasi lingkungan guna mendukung sistem peringatan dini bencana Gunung Sinabung.
\end{abstract}

Kata kunci: komunikasi lingkungan, bencana, Sinabung

\section{Pendahuluan}

Gunung Sinabung di Kabupaten Karo, Sumatera Utara, mengalami bencana terus menerus. Sampai artikel ini ditulis bencana masih terjadi. Ketangguhan masyarakat masih rendah dan proses komunikasi di lingkungan bencana belum berjalan secara efektif. Menurut Oepen and Hamacher, 1999; Chox, 2010, komunikasi lingkungan adalah proses komunikasi secara terencana dan strategis yang digunakan produk media untuk mendukung pembuatan kebijakan yang efektif, partisipasi masyarakat dan pelaksanaan proyek yang diarahkan pada kelestarian lingkungan. Hal ini menjelaskan bahwa sebuah komunikasi lingkungan sebagai interaksi dua arah dari proses sosial yang memungkinkan orang yang bersangkutan untuk memahami faktor-faktor lingkungan tertentu dan saling ketergantungan. Mereka juga merespon masalah dengan cara yang lebih baik 
dengan penggunaan metode ini. Komunikasi lingkungan bertujuan untuk meningkatkan kemampuan masyarakat untuk bisa merespon setiap tanda-tanda yang tepat dari lingkungan dengan kesejahteraan baik peradaban manusia dan sistem biologis alami.

Penelitian ini merujuk pada teori informasi organisasi (West dan Turner 2008: 339-349) yang memiliki sejumlah asumsi dasar, yaitu : (1) Organisasi manusia ada dalam sebuah lingkungan informasi. Asumsi ini menyatakan bahwa organisasi bergantung pada informasi agar dapat berfungsi dengan efektif dan mencapai tujuan mereka. (2) Informasi yang diterima sebuah organisasi berbeda dalam hal ketidakjelasannya. Ketidakjelasan yang dimaksud di sini adalah ambiguitas dalam hal informasi yang diterima oleh organisasi. (3) Organisasi manusia terlibat di dalam pemrosesan informasi untuk mengurangi ketidakjelasan informasi. Dalam upaya mengurangi ambiguitas tersebut, organisasi mulai melakukan aktivitas kerja sama untuk membuat informasi yang diterima dapat dipahami dengan baik. Bencana Gunung Sinabung sangat terkait dengan pengelolaan dan informasi tentang kondisi lingkungan. Guna mengurangi kekacauan informasi, organisasi dalam hal ini BPBD Karo mengupayakan agar informasi tentang lingkungan Gunung Sinabung dapat dikelola secara efektif. Program SMS Gateway Sinabung, radio komunitas, HT, media massa lokal dan nasional serta media sosial merupakan media alternatif memperlancar informasi pra, saat, dan pascabencana Sinabung.
Komunikasi lingkungan sangat dipengaruhi oleh pandangan dunia atau orientasi budaya terhadap Tuhan, kehidupan, kematian, alam semesta, kebenaran, materi (kekayaan) dan isu-isu filosofis lainnya yang berkaitan dengan kehidupan. Perbedaan ideologi dapat menyebabkan perbedaan pandangan atau konsep tentang hubungan antarmanusia dan persepsi manusia tentang realitas di sekelilingnya (Mulyana, 2007). Guna mengatasi berbagai perbedaan persepsi dan kesimpangsiuran informasi tentang bencana erupsi Gunung Sinabung, Teori Informasi Organisasi (West Richard and Lynn H.Turner, 2008: 339) dapat dijadikan pijakan berpikir dan bertindak. Asumsi teori ini bahwa; (1) Organisasi manusia ada dalam sebuah lingkungan informasi, (2) Informasi yang diterima sebuah organisasi berbeda dalam hal ketidakjelasannya, (3) Organisasi manusia terlibat di dalam pemrosesan informasi untuk mengurangi ketidakjelasan informasi.

Gunung Sinabung di Kabupaten Karo Sumatera Utara telah lama tidak erupsi, begitu erupsi mulai tahun 2010, banyak persepsi yang muncul antara lain Sinabung marah, Sinabung memberi peringatan kepada manusia di sekitarnya bahwa hidup harus selalu waspada, Sinabung akan memupuk Tanah Karo agar subur kembali, masyarakat harus melaksanakan adat (sesaji) agar Sinabung berhenti mengeluarkan semburan awan panas dan erupsi yang terus menerus, dan masih banyak persepsi lainnya. Bahkan persepsi tentang bantuan, pengungsi dan relokasi, serta persepsi antara warga masyarakat dan pemerintah juga berlainan dan sempat terjadi konflik antara masyarakat korban dengan 
oknum di Badan Penanggulangan Bencana Daerah (BPBD) yang berujung oknum tersebut diberi sangsi tidak diberi pekerjaan apa-apa. Hal inilah yang mendorong peneliti untuk turut berpartisipasi dalam membentuk masyarakat yang tangguh bencana melalui komunikasi lingkungan yang mengatur informasi agar mudah dimengerti oleh anggota masyarakat terutama yang terdampak bencana.

Lokasi yang berada di sekitar Gunung Sinabung merupakan kawasan risiko tinggi akan terjadinya bencana. Hal ini yang mendasari pentingnya mitigasi bencana guna meningkatkan keselamatan lingkungan, sesuai 9 prioritas pembangunan nasional th 2015-2019. Untuk pelaksanaan mitigasi bencana ini diperlukan komunikasi lingkungan untuk menyampaikan maksud hingga terjadi penerimaan pesan dari seseorang atau sekelompok orang kepada orang lain baik pribadi, kelompok, publik atau secara massal berkaitan dengan situasi dan kondisi lingkungan, baik lingkungan fisik maupun sosial. (Mulyana, 2007) menyatakan komunikasi lingkungan sangat mempengaruhi pandangan dunia atau orientasi budaya terhadap Tuhan, kehidupan, kematian, alam semesta, kebenaran, materi (kekayaan) dan isu-isu filosofis lainnya yang berkaitan dengan kehidupan. Perbedaan ideologi dapat menyebabkan perbedaan pandangan atau konsep tentang hubungan antarmanusia dan persepsi manusia tentang realitas di sekelilingnya.

Hasil penelitian Oepen dan Hamacher (1999) menerangkan bahwa persoalan lingkungan masih banyak terjadi di Indonesia dan muncul di berita-berita televisi, radio, surat kabar, dan media sosial lainnya. Kondisi banjir, tanah longsor, pemanasan global dan gunung meletus, merupakan bagian isu lingkungan yang memerlukan banyak perhatian masyarakat. Ujung dari pemberitaan mengenai isu lingkungan ini tidak luput dari penyelesaian masalah yang selalu berakhir pada kepentingan pribadi atau golongan tertentu yang memanfaatkan situasi, sehingga konflik pun terjadi. Seharusnya konflik tidak perlu terjadi jika semua unsur masyarakat bisa memahami apa yang sebenarnya terjadi tidak semata-mata dilihat dari aspek budaya dan sejarah. Pendapat ini dikuatkan oleh (Cox Robert ; 2010) yang menerangkan dalam perdebatan saat ini pada perkembangan berkelanjutan, komunikasi dan pendidikan sebagai proses dari pembelajaran lingkungan yang memiliki dampak pada setidaknya dua tingkat; 1) Persepsi lingkungan yang sebagian besar ditentukan oleh konteks budaya, visi, gaya hidup dan nilai penilaian yang diperoleh melalui komunikasi; 2) Kriteria dan pilihan untuk keputusan mengenai praktek-praktek berkelanjutan dari wacana publik dan alternatif komunikasi secara transparan. Hal tersebut selanjutnya dapat mengubah persepsi masyarakat dengan menggunakan logika dan penerapan ilmu pengetahuan.

\section{Metode Penelitian}

Penelitian ini temasuk dalam kategori penelitian kualitatif. Pengambilan data dilakukan dengan teknik wawancara mendalam (in dept-interview) melalui pelatihan komunikasi untuk mitigasi bencana Gunung Sinabung dan Focus Group 
Discussion (FGD) di Kabupaten Karo Sumatera Utara khususnya bersama Badan Pengelolaan Bencana Daerah (BPBD), para Kepala Dinas terkait, Camat, Kepala Desa, dan anggota komunitas peduli bencana. Penelitian dilakukan di Kabupaten Karo Sumatera Utara yang merupakan lokasi dari keberadaan Gunung Sinabung. Informan dari penelitian ini adalah Badan Pengelolaan Bencana Daerah (BPBD), para Kepala Dinas terkait, Camat, Kepala Desa, dan anggota komunitas peduli bencana, dan korban bencana.

Instrumen penelitian yang digunakan untuk pengambilan data adalah wawancara mendalam (in dept-interview) dan implementasi model melalui pelatihan komunikasi untuk mitigasi bencana Gunung Sinabung dan Focus Group Discussion (FGD) di Kabupaten Karo Sumatera Utara, bersama Badan Pengelolaan Bencana Daerah (BPBD), para Kepala Dinas terkait, Camat, Kepala Desa, dan anggota komunitas peduli bencana.

Teknik analisis data yang digunakan adalah model analisis data Spreadley (1980) dengan tahapan sebagai berikut:

1. Analisis sebelum ke lapangan. Hasil studi pendahuluan data sekunder untuk menentukan fokus penelitian.

2. Analisis data selama di lapangan. Peneliti melakukan analisis data bersamaan dengan melakukan observasi dan wawancara. Bilamana peneliti merasa belum cukup terpenuhi dengan jawaban informan, peneliti melanjutkan pertanyaan hingga data yang didapatkan valid.

3. Analisis data selesai dari lapangan. Beberapa langkah dilakukan pada tahap ini, antara lain:
- Analisis domain yaitu memberikan gambaran umum dan menyeluruh dari objek panel.

- Analisis taksonomi yaitu penjabarannya serinci dari analisis domain melalui observasi terfokus.

- Analisis komponensial yaitu mencari spesifik pada setiap detail struktur internal, dan

- Analisis tema kultural yaitu mencari hubungan antar data yang hasilnya berupa temuan subtansif dan formal.

Metode analisis data yang digunakan beragam sesuai dengan tahapan penelitian yang dilakukan. Identifikasi mitigasi bencana dikumpulkan dengan wawancara mendalam kemudiandianalisis.Pemunculan ide dan penggabungan ide manajemen komunikasi lingkungan yang baik bagi warga sekitar dilakukan dengan kelompok diskusi (Focus Group Discussion). Setelah diidentifikasi semua jenis persoalan dan cara menanggulanginya, peneliti diskusi dengan tim dan ahli bencana Gunung guna membuat simpulan dan rekomendasi.

\section{Hasil Penelitian dan Pembahasan}

Penelitian ini menemukan model komunikasi lingkungan bencana guna mendukung sistem peringatan dini erupsi Gunung Sinabung yang melibatkan; Badan Nasional Penanggulangan Bencana (BNPB), Bupati, Badan Pengelolaan Bencana Daerah (BPBD), Kepala Dinas Sosial, Kominfo, Kesatuan Bangsa dan Perlindungan Masyarakat (Kesbanglimas), Kepolisian, Tentara Nasional Indonesia TNI), Camat, Kepala Desa, komunitas-komunitas peduli bencana, dan masyarakat. (Gambar 1). 


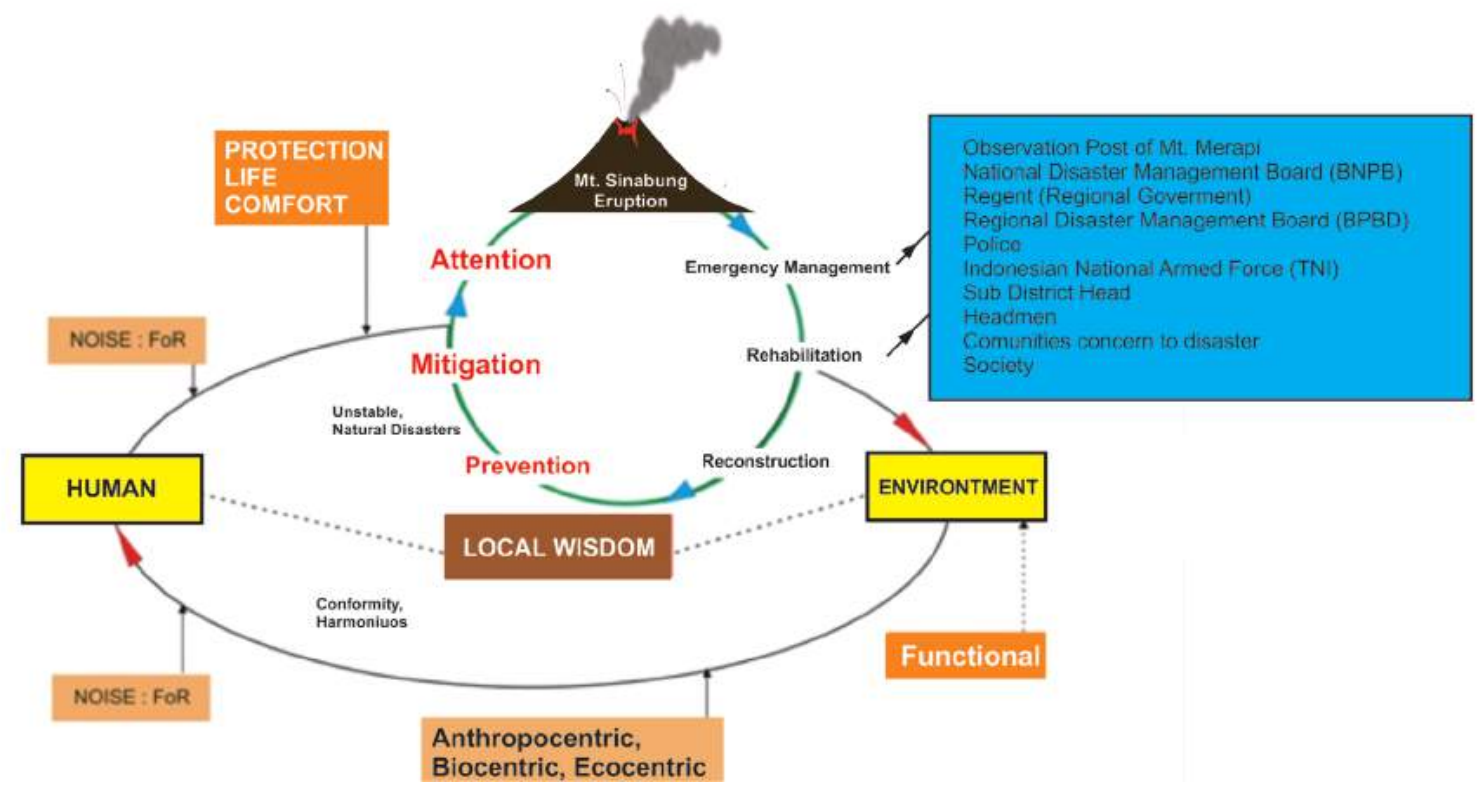

Gambar 1. Model Komunikasi Lingkungan dan Bencana Gunung Sinabung

Siklus model komunikasi lingkungan dan bencana menunjukkan bahwa menyikapi bencana diperlukan tahapan manajemen. Dalam mitigasi bencana Gunung Sinabung ini ada dua hal yang saling bersangkutan yaitu manusia dan lingkungan serta dua tahapan manajemen bencana yaitu manajemen risiko dan manajemen krisis. Manajemen risiko meliputi kesiapsiagaan, mitigasi, dan pencegahan yang nantinya akan menghasilkan sebuah perlindungan, kehidupan, dan kenyamanan bagi seluruh masyarakat Gunung Sinabung. Manajemen risiko ini erat hubungannya dengan perencanaan pembangunan oleh pemerintah pusat daerah antara lain Badan Nasional Penanggulangan Bencana (BNPB), Bupati, Badan Pengelolaan Bencana Daerah (BPBD), Kepala Dinas Sosial, Kominfo, Kesatuan Bangsa dan Perlindungan Masyarakat (Kesbanglimas), Kepolisian, Tentara Nasional Indonesia TNI), Camat, Kepala Desa, komunitas-komunitas peduli bencana, dan masyarakat. Pemerintah dalam melaksanakan komunikasi lingkungan bencana tidak berjalan lancar karena adanya bebagai gangguan baik dari sisi lingkungan maupun manusianya. Manajemen yang dilakukan setelah terjadi bencana ialah manajemen krisis meliputi penanganan darurat, rehabilitasi, dan rekonstruksi yang berujung pada keadaan lingkungan dan masyarakat yang sebelumnya kurang stabil menjadi stabil.

Temuan pada gambar 1 masih perlu didiskusikan lebih lanjut terkait kelengkapan unsur-unsur komunikasi lingkungan bencana gunung berapi seperti alur informasi ketika terjadi bencana. Sebagai perbandingan, model manajemen komunikasi bencana Gunung Merapi 2010 (Lestari, Agung Prabowo, dan Arif Wibawa, 2012: 8) lebih lengkap, yang melibatkan lingkungan fisik seperti bandara, kelompok-kelompok masyarakat, teknologi informasi dan komunikasi. Lingkungan bencana Gunung Merapi lebih responsif dibandingkan lingkungan bencana 
Gunung Sinabung. Di Yogyakarta, banyak masyarakat yang terlibat aktif menyebarkan informasi melalui komunikasi kelompok seperti Forum Penenggulangan Risiko Bencana (FPRB), Jaringan Informasi Lingkar Merapi, Lembaga Swadaya Masyarakat (LSM) Combine, akun media sosial kelompok (Facebook dan Twitter), dan radio-radio streaming komunitas (Gambar 2).

Model Komunikasi Lingkungan dan Bencana Gunung Sinabung memiliki unsur budaya lokal Karo yang berbeda dengan budaya Jawa. Menurut hasil penelitian Lestari, Eko Teguh, dan Sari Bahagiarti (2015:104) kearifan lokal masyarakat sekitarGunung Sinabung terdiri dari; Bahasa lokal Karo, Jambur (Tempat pertemuan pengungsi), Filosofi, Ekologi, Sistem Kekerabatan, dan Budaya Kerja Tahun (pesta tahunan sebagai ungkapan syukur).
Masyarakat Karo memiliki kecenderungan konflik lebih tinggi. Lingkungan fisik yang berbukit dan jarak antar kampung jauh juga memengaruhi karakter masyarakat relatif lebih keras. Hal ini menjadi penghambat komunikasi lingkungan di saat bencana Gunung Sinabung.

Beberapa hal yang harus dilakukan dalam upaya kesiapsiagaan dan mitigasi bencana Gunung Berapi (http://www. psmbupn.org/consul/kesiapsiagaan-danmitigasi-bencana-gunung-api.html) bahwa: (1) Masyarakat tangguh bencana hendaknya mengenal karakteristik ancaman di wilayah yang rawan bencana. (2) Menganalisis risiko bencana dengan melakukan analisis ancaman, analisis kerentanan dan analisis kemampuan. (3) Membangun jaringan komunikasi di masyarakat lewat radio $\mathrm{HT}$, Hp, jaringan internet, untuk mengakses informasi-informasi baik dari

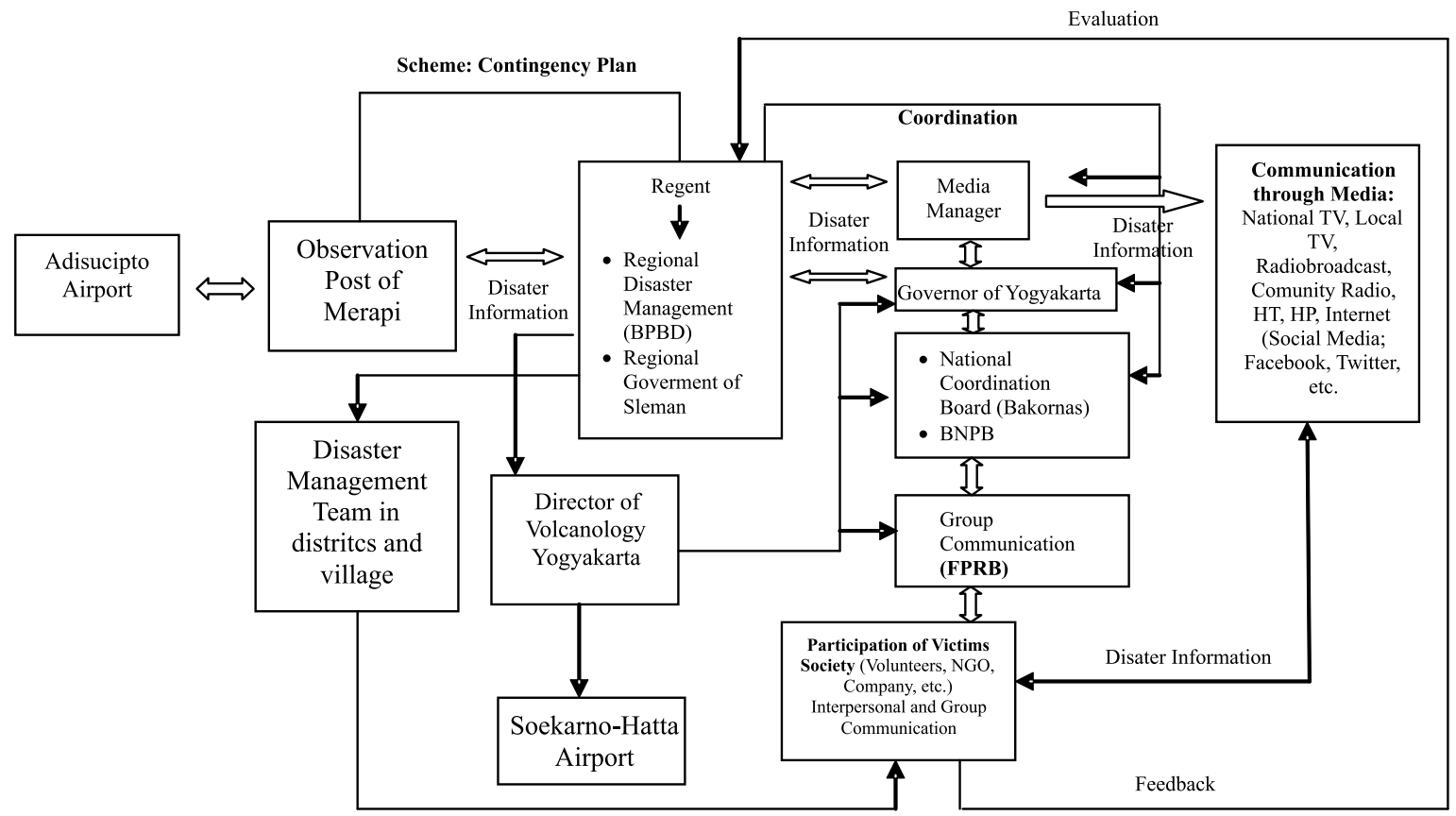

Gambar 2. Model Manajemen Komunikasi Bencana Merapi 2010 saat Tanggap Darurat (Sumber; Lestari, Puji, Agung Prabowo, and Arif Wibawa, Manajemen Komunikasi Bencana Merapi 2010 pada saat Tanggap Darurat, Jurnal Ilmu Komunikasi Universitas Pembangunan Nasional (UPN) Veteran Yogyakarta, Vol 10 No 2, Agustus (2012), 173-197. 
pemerintah maupun masyarakat secara up to date tentang kondisi gunung api. (5) Adanya rencana aksi daerah (RAD) atau rencana kontijensi di tingkat pemerintah Provinsi, Kabupaten hingga rencana aksi kampung (RAK) di tingkat masyarakat, yang merupakan kegiatan-kegiatan dalam upaya pengurangan risiko bencana (PRB), seperti pelatihan tentang kebencanaan, membangun sarana-sarana peringatan dini, membangun jaringan komunikasi dan sebagainya. (6) Adanya kerjasama setiap pihak terutama masyarakat yang berada di sekitar kawasan rawan bencana gunung api (7) Memfokuskan kegiatankegiatan untuk mengurangi risiko sebelum terjadinya erupsi gunung api. (8) Mitigasi bencana yaitu upaya-upaya yang dilakukan di masyarakat untuk mengurangi kerentanan-kerentanan dan meningkatkan kemampuan masyarakat untuk mengurangi risiko bencana, contohnya: pelatihan kebencanaan, pelatihan penanggulangan gawat darurat (PPGD) dan lain-lain. Pemerintah dan masyarakat Kabupaten Karo khususnya sekitar Gunung Sinabung sebaiknya selalu siap siaga dan menjadi tangguh bencana.

Hasil penelitian ini mendukung arah kebijakan umum pembangunan nasional 2015-2019 ke 4 mengenai peningkatan kualitas lingkungan hidup, Mitigasi bencana alam dan perubahan iklim. Bahwa arah kebijakan peningkatan kualitas lingkungan hidup, mitigasi bencana dan perubahan iklim adalah melalui peningkatan pemantauan kualitas lingkungan dan penegakan hukum pencemaran lingkungan hidup; perkuatan kapasitas mitigasi bencana alam untuk mengurangi resiko bencana, mempercepat rehabilitasi daerah yang terkena bencana, dan memperkuat kapasitas mitigasi dan adaptasi perubahan iklim. Guna mewujudkan kualitas lingkungan dan perkuatan kapasitas mitigasi bencana alam untuk mengurangi resiko bencana dilakukan pemberdayaan masyarakat melalui komunikasi lingkungan untuk mitigasi bencana khususnya Gunung Sinabung yang masih berpotensi menimbulkan bencana alam. Hal tersebut mendukung penemuan Lestari, dkk (2014) Komunikasi lingkungan bencana tidak terlepas dari manajemen komunikasi pihakpihak terkait bencana. Kondisi Sinabung berbeda dengan komunikasi lingkungan bencana Merapi. Hasil penelitian Lestari, dkk (2010) tentang manajemen komunikasi bencana Merapi 2010 yaitu manajemen komunikasi partisipatif, pada prinsipnya sudah sesuai dengan ketentuan UU Penanggulangan Bencana Nomor 24 tahun 2007 Pasal 33 huruf b. Bahwa penyelenggaraan penanggulangan bencana pada saat tanggap darurat meliputi: (I) Pengkajian secara cepat dan tepat terhadap lokasi, kerusakan, dan sumber daya; (2) Penentuan status keadaan darurat bencana; (3) Penyelamatan dan evakuasi masyarakat terkena bencana; (4) Pemenuhan kebutuhan dasar; (5) Perlindungan terhadap kelompok rentan; dan (6) Pemulihan dengan segera Prasarana dan sarana vital. Pada tahap penilaian kondisi darurat sudah dilakukan suatu proses komunikasi kelompok yaitu mengumpulkan informasi atau data secara 
sistematis dengan manajemen komunikasi partisipatif oleh warga RT/RW, dukuh, desa, kecamatan. kabupaten, selanjutnya petugas menganalisis situasi untuk menentukan dan menilai kondisi-kondisi korban apakah rusak ringan, sedang, atau berat serta jumlah yang meninggal, sakit parah, ringan. dan sebagainya. Pada tahap ini dilakukan proses komunikasi antara petugas dengan masyarakat korban di lokasi bencana, komunikasi dengan aparat pemerintah setempat, dan pihak-pihak terkait untuk melakukan monitoring dan refleksi yang berlangsung terus-menerus guna membantu perencanaan program yang cocok dengan kondisi dan kebutuhan masyarakat korban.

\section{Simpulan}

Komunikasi lingkungan di daerah bencana tidak terlepas dari tingkat pengetahuan dan sikap tentang berbagai hal yang berkaitan dengan bencana lingkungan, baik bencana lingkungan fisik maupun lingkungan masyarakat dan pemerintah. Pengetahuan adalah dasar bagi pembentukan keyakinan. Keyakinan tersebut pada tahap berikutnya menjadi bahan pertimbangan untuk menentukan sikap dan perilaku, termasuk sikap dan perilaku tangguh bencana. Di sisi lain, komunikasi lingkungan merupakan wahana untuk memberikan pengetahuan dan pemahaman kepada masyarakat mengenai perencanaan lingkungan yang baik agar berfungsi efektif dan memberikan manfaat yang maksimal bagi terciptanya perilaku masyarakat yang kondusif terhadap lingkungan. Perecanaan komunikasi ling- kungan yang baik perlu dilakukan terutama di daerah sekitar Sinabung yang masih diperkirakan erupsi sampai lima tahun ke depan. Masyarakat diharapkan mampu membangun kesepahaman dengan masyarakat lain bahkan dengan pemerintah daerah dan pusat, agar permasalahan lingkungan di daerah bencana Sinabung ini ada alternatif solusi yang bisa diupayakan secara bersama melalui perilaku dan tindakan masyarakat secara mandiri.

Substansi penelitian ini merekomendasikan agar Pemerintah Daerah Karo melakukan proses perencanaan dan perancangan komunikasi lingkungan yang strategis dan bermanfaat dalam memetakan setiap permasalahan lingkungan terutama di daerah rawan bencana. Pemangku kepentingan memberikan arah yang jelas dalam menyusun strategi komunikasi lingkungan yang efektif bagi terciptanya perubahan perilaku yang positif untuk mendukung kesejahteraan masyarakat dan secara khusus bagi para korban bencana Sinabung. Kegiatan perancangan komunikasi lingkungan membutuhkan kompetensi soft dan hard dalam perencanaan, dan juga membutuhkan wawasan komunikasi lingkungan yang komprehensif. Berkaitan dengan hal tersebut, para pejabat yang terkait dengan fungsi perencanaan komunikasi lingkungan seharusnya memiliki kompetensi tersebut dan sekaligus memiliki wawasan komunikasi lingkungan dan komunikasi bencana yang komprehensif. Guna meningkatkan kompetensi tersebut sangat diperlukan bimbingan teknis perancangan komunikasi lingkungan yang diperuntukaan bagi pejabat dan staf BPBD dan Kominfo, Badan Lingkungan Hidup Daerah, dan Satuan Kerja 
PemerintahDaerah(SKPD)terkaitpenanganan komunikasi lingkungan di daerah rawan bencana. Tujuan dilaksanakannya bimbingan teknis ini untuk memberikan pemahaman konsep dan model perencanaan komunikasi lingkungan yang komprehensif dan meningkatkan kemampuan dan keterampilan dalam menyusun perencanaan komunikasi lingkungan hidup yang efektif. Adapun materi pelatihan mengenai perancangan komunikasi lingkungan yang disesuaikan dengan kondisi dan permasalahan lingkungan yang esensial di daerahnya (isu lokal). Selain itu, peserta diberikan kesempatan untuk memaparkan program-program kampanye dan publikasi yang dilakukan selama ini, kemudian mereka dibekali pengetahuan dan keterampilan untuk merancang program-program kampanye dan publikasi yang efektif dan tepat sasaran.

\section{Daftar Pustaka}

Cox, Robert. Environmental Communication and the Public Sphere, Sage Publication. US, 2010

Lestari, Puji, Agung Prabowo, and Arif Wibawa, Manajemen Komunikasi Bencana Merapi 2010 pada saat Tanggap Darurat, Jurnal Ilmu Komunikasi UPN
Veteran Yogyakarta, Vol 10 No 2, Agustus (2012), 173-197

Lestari, Puji, Eko Teguh Paripurno, and Sari Bahagiarti, Local Wisdom as Alternative of Disaster Communication Management in Mount Sinabung Karo Regeny North Sumatera Indonesia, The Indonesian Journal of Communication Studies, Vol 8 No 1, June (2015), 101111.

Mulyana, Deddy. (2001) Komunikasi Suatu Pengantar. Bandung: Rosda Karya.

Oepen, Manfred and Hamacher, Winfried. (1999). Environmental Communication for Sustainable Development. Frankrut: Peter Lang.

West, Richard and Lynn H.Turner. (2008). Pengantar Teori Komunikasi, Analisis dan Aplikasi. Buku 1. Jakarta : Salemba Humanika.

\section{Internet}

http://elib.pdii.lipi.go.id/katalog/index.php/ searchkatalog/byId/290836. Pusat Dokumentasi dan Informasi Ilmiah Lembaga Ilmu Pengetahuan Indonesia PDII-LIPI diakses 30 Agustus 2015.

http://www.psmbupn.org/consul/kesiapsiagaandan-mitigasi-bencana-gunung-api.html diakses 22 Oktober 2015. 